\title{
Disruption in time projection and non-adherence to long-term therapies
}

This article was published in the following Dove Press journal:

Patient Preference and Adherence

\author{
Gérard Reach ${ }^{1,2}$ \\ Marouane Boubaya ${ }^{3}$ \\ Yoann Brami' \\ Vincent Lévy 3,4 \\ 'Department for Endocrinology, \\ Diabetes and Metabolic Diseases, \\ Avicenne Hospital, APHP, Bobigny, \\ France; ${ }^{2}$ EA 34I2, Health Education \\ and Practices Laboratory (LEPS), Paris \\ 13 University, Sorbonne Paris Cité, \\ Bobigny, France; ${ }^{3}$ Clinical Research \\ Unit and Clinical Research Center, \\ Avicenne Hospital, APHP, Bobigny, \\ France; ${ }^{4}$ INSERM UMR II 53 (Centre \\ of Research in Epidemiology and \\ Statistics, Sorbonne Paris Cité), \\ ECSTRRA team (Epidemiology \\ and Clinical Statistics for Tumor, \\ Respiratory, and Ressuscitation \\ Assessments), Hôpital Saint Louis, \\ Paris, France
}

Objective: Patients' non-adherence to medical prescriptions is a crucial issue in contemporary medicine because it can jeopardize care efficacy. Non-adherence is especially frequent in patients with chronic diseases. In this article, we propose that a particular condition, which we call disruption in time projection, is a cause of non-adherence to medication therapies in chronic diseases.

Methods: A questionnaire was administered to 120 hospitalized people with type 2 diabetes addressing three psychological constructs defining time projection: patience/impatience in a fictive monetary scenario (preferring to receive $€ 1,500$ in 1 year or $€ 500$ today), magnitude of temporal horizon (greater or lesser ability to imagine future events) and perception of the degree of physical similarity of current self to self at 1 year, 5 years and 10 years from the present. In addition, the questionnaire evaluated adherence to medication, social deprivation and depression.

Results: In the multivariate analyses, two factors were associated with adherence to medication: patience $(P<0.001)$ and long temporal horizon $(P=0.006)$. Two factors were associated with $\mathrm{HbA} 1 \mathrm{c} \geq 8 \%(64 \mathrm{mmol} / \mathrm{mol})$ : non-adherence to medication $(P=0.003)$ and short temporal horizon $(P=0.011)$. Three factors were associated with long temporal horizon: adherence to medication $(P<0.001)$, patience $(P<0.001)$ and the existence of grandchildren $(P=0.002)$. Social deprivation $(P<0.001)$, non-adherence $(P<0.001)$, female gender $(P=0.002)$ and short temporal horizon $(P=0.050)$ were associated with impatience. Finally, an association of adherence to expected similarity in the future to current self, impatience, short temporal horizon, social deprivation and depression was also shown in a multiple correspondence analysis.

Conclusion: What we termed a disruption in time projection may be a unique determinant for non-adherence to long-term therapy and, therefore, may influence the outcome of chronic diseases. We hypothesize that this is involved in both intentional and unintentional non-adherence and that it represents the loss of a protective mechanism. If this novel concept is to be confirmed in other settings and generalized to other chronic diseases, the recognition of its role in disease prognosis may help orient the teaching and practice of medicine.

Keywords: adherence, temporal horizon, impatience, disruption in time projection, social deprivation, depression, type 2 diabetes, chronic diseases

\section{Introduction}

Non-adherence to medication occurs frequently and can jeopardize the efficacy of longterm therapies. In people with diabetes, it is associated with reduced effectiveness of medications on $\mathrm{HbA1c},{ }^{1}$ higher risks of complications, increased rates of hospitalization, greater health care costs and higher mortality. ${ }^{2,3}$ Thus, non-adherence is a crucial issue for contemporary medicine: ${ }^{4}$ Haynes, quoted by the WHO, stated that "Increasing the effectiveness of adherence interventions may have a far greater impact on the health of the population than any improvement in specific medical treatment". ${ }^{4}$
Correspondence: Gérard Reach Direction Qualité, Hôpital Avicenne APHP, 125 route de Stalingrad, 93000 Bobigny, France Tel +33 148957099

Email gerard.reach@aphp.fr (c) (1) (5) 2018 Reach et al. This work is published and licensed by Dove Medical Press Limited. The full terms of this license are available at https://www.dovepress.com/terms.php (c) $\mathrm{BY}$ and incorporate the Creative Commons Attribution - Non Commercial (unported, v3.0) License (http://creativecommons.org/licenses/by-nc/3.0/). By accessing the work you hereby accept the Terms. Non-commercial uses of the work are permitted without any further permission from Dove Medical Press Limited, provided the work is properly attributed. For permission for commercial use of this work, please see paragraphs 4.2 and 5 of our Terms (https://www.dovepress.com/terms.php). 
In general, it is believed that non-adherence to medication is driven by patient factors, type of therapy (complexity and side effects), quality of the patient-physician relationship ${ }^{5-7}$ and the overall health care system. ${ }^{4}$ However, one characteristic of non-adherence has been less attended to so far: non-adherence to long-term therapies concerns chronic diseases specifically, which form the largest part of the burden of health care at present. This suggests that the patients' relationship to temporality may be key to understanding the basic mechanisms of adherence: if the choice between adherent and non-adherent behavior is driven by the attractiveness of their respective rewards, it can be expected that a significant number of patients will choose non-adherence, whose reward is immediate and concrete, while the reward for adherence (avoiding complications) is abstract and remote. ${ }^{8}$ Consistent with this idea, non-adherence has been found to be more frequent in younger people, for whom the prospect of living with the disease may entail a longer time duration. ${ }^{9}$ Non-adherence is also more frequent in socially deprived patients, ${ }^{10}$ whose most immediate priorities may not include their health status. Thus, we hypothesized that being adherent is associated with giving priority to the future. ${ }^{11,12}$

Therefore, this work tested the hypothesis that adherence to medication in chronic diseases is linked to time projection, defined herein as consisting of three psychological constructs: patience/impatience, size of temporal horizon (greater or lesser ability to imagine remote future events) and perception of the degree of physical similarity of current self to future self. This study was performed on people with type 2 diabetes; therefore, in addition, we investigated the connection between time projection and $\mathrm{HbA} 1 \mathrm{c}$ levels.

\section{Research design and methods}

This study included a sample of 120 people with type 2 diabetes (65 men and 55 women), who were hospitalized, either for diabetic complications or for insufficient diabetes control, at a university hospital in the north suburb of Paris. Terminal kidney failure was an exclusion criterion. The study period lasted from May 19, 2016 to February 21, 2017. Recruitment continued until the final sample size of the study $(n=120)$ was reached; this was intended to be larger than that of a previous study $(\mathrm{n}=80)$ describing the association between the temporal horizon and smoking habits. ${ }^{13}$ The study was approved in April 2016 by an Ethical Review Board (Comité Consultatif sur le Traitement de l'Information en matière de Recherche Scientifique, C.C.T.I.R.S.). All patients received a document explaining the study and indicating that they were free to accept or refuse filling up the questionnaire, and gave their written informed consent for their participation.
To prevent missing data, the questionnaire was administered in the presence of a resident (YB) who explained the questions if needed. The questionnaire included the following categories. 1) Demographic data: gender, age, time since diagnosis of diabetes (referred to below as diabetes duration), marital status and existence of children and grandchildren, employment status, body mass index (BMI), last documented $\mathrm{HbA1c}$ level, smoking status and the presence of complications of diabetes. 2) Adherence to medication, assessed using the French six-item validated Girerd questionnaire, with questions such as "Do you think that you have too many tablets to take?" People were considered non-adherent if the number of positive responses to the items was $\geq 3 .{ }^{14} 3$ ) Impatience, determined using a simple fictive monetary scenario: if you are offered $€ 500$ today or $€ 1,5001$ year from now, what would you choose? ${ }^{15}$ 4) Temporal horizon, judged using two methods: ${ }^{13}$ first, patients were asked to list five events that would happen to them and indicate their expected age when they occurred; the temporal horizon (in years) was determined as the difference between age at the final event and the patient's current age. Second, they were asked to complete the following story- "Joe, drinking his coffee, starts to think of the future. He thinks that" - and give the duration of the end they had imagined. 5) The degree of physical similarity of one's present self to the future self was determined by asking patients how they imagined they would look like physically, in comparison to today, in 1 month, 1 year, 5 years and 10 years. ${ }^{16} 6$ ) Social deprivation was measured using the 11-item EPICES questionnaire, with scores $>30$ indicating social deprivation. ${ }^{17}$ Finally, depression was assessed with the 13-item (short-form) Beck Depression Inventory questionnaire, with scores greater than four indicating depression. ${ }^{18}$ The complete questionnaire had 45 items and can be obtained from the main author by request. Questions asked to the patients to collect their demographic data and to address time projection are to be found in Figure A1. The Girerd questionnaire (adherence), EPICES (social deprivation) and the Beck questionnaire (depression) can be found elsewhere. ${ }^{14,17,18}$ Finally, we used the two first questions of the 13-item depression Beck's questionnaire to indicate pessimism and sadness, respectively.

\section{Data analyses}

The primary outcome was adherence to medication. The results were dichotomised into adherent $(<3$ positive answers to the Girerd questionnaire) and non-adherent $(\geq 3){ }^{14}$ Logistic regression was performed to evaluate associations with patient characteristics. HbAlc was dichotomised into $<8$ or $\geq 8 \%(8 \%=64 \mathrm{mmol} / \mathrm{mol})$, indicating acceptable or poor metabolic control in these hospitalized patients and logistic regression was used to calculate the determinants 
of HbA1c. The determinants of temporal horizon and impatience were analyzed using negative binomial regression and logistic regression, respectively. Repeated-measures ANOVA were used to perform the comparison of the evolution of the degree of similarity over time between adherent and non-adherent patients. Finally, a multiple correspondence analysis (MCA) was performed, using the parameters selected from the previous results: HbA1c $(<8 / \geq 8 \%,<64 / \geq 64 \mathrm{mmol} / \mathrm{mol})$, age $(<60 / \geq 60$ years old $)$, diabetes duration $(\leq 10 / 10-20 />20$ years $)$, grandchildren (yes/no), impatience/patience in the monetary choice, smoking status (never/quit/active), temporal horizon $(\leq 1 / 2-5 />5$ years), treatment adherence/non-adherence $(0-2 / \geq 3$ positive answer), physical self-similarity at 10 years $(>50 / \leq 50 \%)$, social deprivation (yes/no), depression (yes/no) and pessimistic/non-pessimistic and sad (yes/no) answers in the depression questionnaire. Euclidean distances and Ward's method were used to perform unsupervised hierarchical clustering on all the dimensions of the MCA. Clusters were defined by cutting branches off the dendrogram.

There were no missing data. All the tests were two-sided at a significance level of $P<0.05$. R statistical software version 3.1.2 (R Foundation for Statistical Computing, Vienna, Austria) was used to conduct the analyses.

\section{Results}

\section{Demographical and psychological data}

In all, 120 patients were included in the study. Recruitment was limited only by refusal to participate or inability to read and write or understand the questionnaire, either due to a linguistic barrier or limited literacy, as is frequently met with in this hospital. The mean age of the patients was $58.6 \pm 8.9$ years old and the mean diabetes duration was $14.5 \pm 8.9$ years. A mean BMI of $29.0 \pm 5.4 \mathrm{~kg} / \mathrm{m}^{2}$ was found, and their mean $\mathrm{HbA} 1 \mathrm{c}$ levels were $9.8 \% \pm 2.4 \%(84 \pm 14.5 \mathrm{mmol} / \mathrm{mol})$. In all, $90.8 \%$ of the patients had children and $47.5 \%$ had grandchildren. Of the total, $44.2 \%$ never smoked, $27.5 \%$ were active smokers and $27.5 \%$ had quit smoking.

Table 1 presents the complete demographic description of the patients.

Table 2 presents the results of the psychosocial questionnaires. Only one-third of the patients gave fewer than three positive answers to the Girerd questionnaire, which would be consistent with adherent status. One-third gave the patient answer to the monetary choice question (preferring waiting 1 year for $€ 1,500$ ), half were socially deprived and one-third showed signs of depression, sadness and pessimism. The median temporal horizon was found to be 2.5 years for the eventdetermination method and 30 days for the story determination method. The degree of expected physical similarity of the future to the current self decreased progressively over time, reaching $43.3 \%$ at 10 years, but with large standard deviations.

\section{Determinants of adherence to medication}

In the univariate analysis (the results of which are given in Table 3), the following characteristics were associated with adherence to medication (defined as fewer than three

Table I Demographic description of the sample population

\begin{tabular}{|c|c|c|c|c|}
\hline Characteristics & Median & QI:Q3 & & \\
\hline Age (years) & 59 & $(53: 67)$ & & \\
\hline Diabetes duration & 14 & $(8: 21)$ & & \\
\hline $\mathrm{HbAlc}(\%)(\mathrm{mmol} / \mathrm{mol})$ & $9.2(77)$ & $(8.3: 11.0)(67.2: 96.7)$ & & \\
\hline $\mathrm{BMI}\left(\mathrm{kg} / \mathrm{m}^{2}\right)$ & 28.9 & $(25.6: 32.4)$ & & \\
\hline Gender & Female & & & \\
\hline N (\%) & $55(45.8 \%)$ & & & \\
\hline Marital status & Married & Living as a couple & Divorced & Widow/er \\
\hline N (\%) & $70(58.3 \%)$ & $8(6.7 \%)$ & $13(10.8 \%)$ & $13(10.8 \%)$ \\
\hline Children & $109(90.8 \%)$ & & & \\
\hline Grandchildren & 57 (47.5\%) & & & \\
\hline Professional activity & Unstable & No employment & In search of employment & Disability \\
\hline N (\%) & $12(10 \%)$ & $79(58.3 \%)$ & $5(4.2 \%)$ & $7(5.8 \%)$ \\
\hline Treatment & OAD & OAD + insulin & Basal bolus & \\
\hline $\mathrm{N}(\%)$ & $32(26.7 \%)$ & $23(19.2 \%)$ & $65(54.2 \%)$ & \\
\hline Smoking habits & Quit & Active & Never & \\
\hline N (\%) & $33(27.5 \%)$ & $34(27.5 \%)$ & $53(44.2 \%)$ & \\
\hline Complications & Stent & Neuropathy & Retinopathy & \\
\hline N (\%) & $16(13.3 \%)$ & $68(56.7 \%)$ & $57(47.5 \%)$ & \\
\hline
\end{tabular}

Note: Bold figures represent statistically significant.

Abbreviations: BMI, body mass index; OAD, oral antidiabetic drug. 
Table 2 Answers to the psychological questionnaires

\begin{tabular}{|c|c|}
\hline Characteristics & Value \\
\hline \multicolumn{2}{|l|}{ Adherence (Girerd questionnaire) } \\
\hline Number of positive answers, median (QI:Q3) & $3(1: 4)$ \\
\hline$<3$ positive answers (adherent), $\mathrm{n}(\%)$ & $47(39.2 \%)$ \\
\hline \multicolumn{2}{|l|}{$\begin{array}{l}\text { Impatience/patience (monetary choice), } \\
\text { n (\%) }\end{array}$} \\
\hline Prefer $€ 500$ now (impatient) & $76(63.3 \%)$ \\
\hline Prefer $€ I, 500$ in a year (patient) & $44(36.7 \%)$ \\
\hline \multicolumn{2}{|l|}{ Temporal horizon } \\
\hline Events method (years), median (QI:Q3) & $2.5(1: 5)$ \\
\hline Story method (days), median (QI:Q3) & $30(2: 3,650)$ \\
\hline \multicolumn{2}{|l|}{ Similarity to current self, mean \pm SD } \\
\hline I month & $97.3 \pm 10$ \\
\hline I year & $87.8 \pm 13.1$ \\
\hline 5 years & $67.4 \pm 23.2$ \\
\hline 10 years & $43.3 \pm 30.5$ \\
\hline \multicolumn{2}{|l|}{ Social deprivation (EPICES questionnaire) } \\
\hline Score, median (QI:Q3) & $28.7(21.9: 51.5)$ \\
\hline Socially deprived (score $>30), \mathrm{n}(\%)$ & $55(45.8 \%)$ \\
\hline \multicolumn{2}{|l|}{ Depression (Beck Depression Inventory) } \\
\hline Score, median (QI:Q3) & $2(0: 5)$ \\
\hline Depressed (score $>4$ ), n (\%) & $43(35.8 \%)$ \\
\hline Not sad, n (\%) & $82(68.3 \%)$ \\
\hline Not pessimistic, n (\%) & 35 (29.2\%) \\
\hline
\end{tabular}

Note: Sad and pessimistic are assessed using the answers to the two first questions in the Beck Depression Inventory. positive answers in the Girerd questionnaire): long temporal horizon, as determined by the event method (OR, 1.24; 95\% CI, 1.11-1.38; $P<0.001)$, impatient answer for the monetary choice question (OR, 0.11; 95\% CI, 0.05-0.26; $P<0.001), \mathrm{HbA} 1 \mathrm{c} \geq 8 \%(64 \mathrm{mmol} / \mathrm{mol})$ (OR, $0.02 ; 95 \%$ CI, 0.01-0.18; $P<0.001$ ), depression (OR, 0.22; 95\% CI, 0.09-0.054; $P<0.001$ ), social deprivation (OR, $0.39 ; 95 \%$ CI $0.18-0.83 ; P=0.015)$ and age $\geq 60$ years old (OR, 2.11; $95 \% \mathrm{CI}, 1.00-4.45 ; P=0.050)$. In addition, we observed that the degree of expected physical similarity with the current aspect at 1 year, 5 years and 10 years was higher in adherent people (Figure 1); however, this trend did not reach statistical significance $(P=0.09)$.

In multivariate analysis, using all these variables with the exception of $\mathrm{HbA} 1 \mathrm{c}$, two factors only were found to be significantly associated with adherence to medication: impatience (OR, 0.20; 95\% CI, 0.08-0.51; $P=0.006)$ and long temporal horizon (OR, 1.17; 95\% CI 1.05-1.31; $P=0.006)$. When temporal horizon was excluded from multivariate analysis, two determinants were found associated with adherence: impatience (OR, 0.14; 95\% CI, 0.06-0.35; $P<0.001)$ and depression (OR, 0.38; 95\% CI 0.14-1.02;

Table 3 Univariate analysis of adherence (Girerd questionnaire)

\begin{tabular}{|c|c|c|c|}
\hline Characteristics & Category & OR $(95 \% \mathrm{Cl})$ & $P$-value \\
\hline Age (years) & $\geq 60$ & $2.11(1.00-4.45)$ & 0.050 \\
\hline $\mathrm{HbAlc}$ & $\begin{array}{l}\geq 8 \% \\
(64 \mathrm{mmol} / \mathrm{mol})\end{array}$ & $0.02(0.01-0.18)$ & $<0.001$ \\
\hline Temporal horizon (events method) & & $1.24(1.11-1.38)$ & $<0.001$ \\
\hline Social deprivation (EPICES questionnaire) & Score $>30$ & $0.39(0.18-0.83)$ & 0.015 \\
\hline Patience/impatience in monetary choice & Impatient & $0.11(0.05-0.26)$ & $<0.001$ \\
\hline Depression (Beck Depression Inventory) & Score $>4$ & $0.22(0.09-0.54)$ & $<0.001$ \\
\hline Gender & Female & I.4I (0.68-2.95) & 0.36 \\
\hline Activity & Stable & $0.63(0.25-1.59)$ & 0.32 \\
\hline Marital status & Couple & $0.92(0.43-1.98)$ & 0.83 \\
\hline Children & Yes & $1.14(0.31-4.13)$ & 0.84 \\
\hline Grandchildren & Yes & I.I $(0.53-2.29)$ & 0.80 \\
\hline BMI & $>24$ & $1.09(0.43-2.75)$ & 0.85 \\
\hline \multirow[t]{3}{*}{ Smoking status } & Quit & 1.00 & \\
\hline & Never & $0.73(0.3-1.76)$ & 0.48 \\
\hline & Active & $0.65(0.25-1.75)$ & 0.40 \\
\hline Diabetes duration (years) & & $1.02(0.98-1.06)$ & 0.32 \\
\hline Retinopathy & Yes & $0.96(0.46-1.99)$ & 0.90 \\
\hline Neuropathy & Yes & $1.4(0.67-2.96)$ & 0.37 \\
\hline Stent & Yes & $1.67(0.58-4.8)$ & 0.34 \\
\hline Treatment & Basal insulin & $0.94(0.45-1.96)$ & 0.86 \\
\hline Similarity at I year (\%) & & $1.01(0.98-1.04)$ & 0.59 \\
\hline At 5 years & & $1.01(0.99-1.03)$ & 0.29 \\
\hline At 10 years & & $1.01(1.00-1.02)$ & 0.064 \\
\hline Sad (Beck Depression Inventory) & Yes & $0.52(0.23-1.19)$ & 0.12 \\
\hline Pessimistic (Beck Depression Inventory) & Yes & $0.52(0.22-1.21)$ & 0.13 \\
\hline
\end{tabular}

Note: Bold figures represent statistically significant. Abbreviation: BMI, body mass index. 


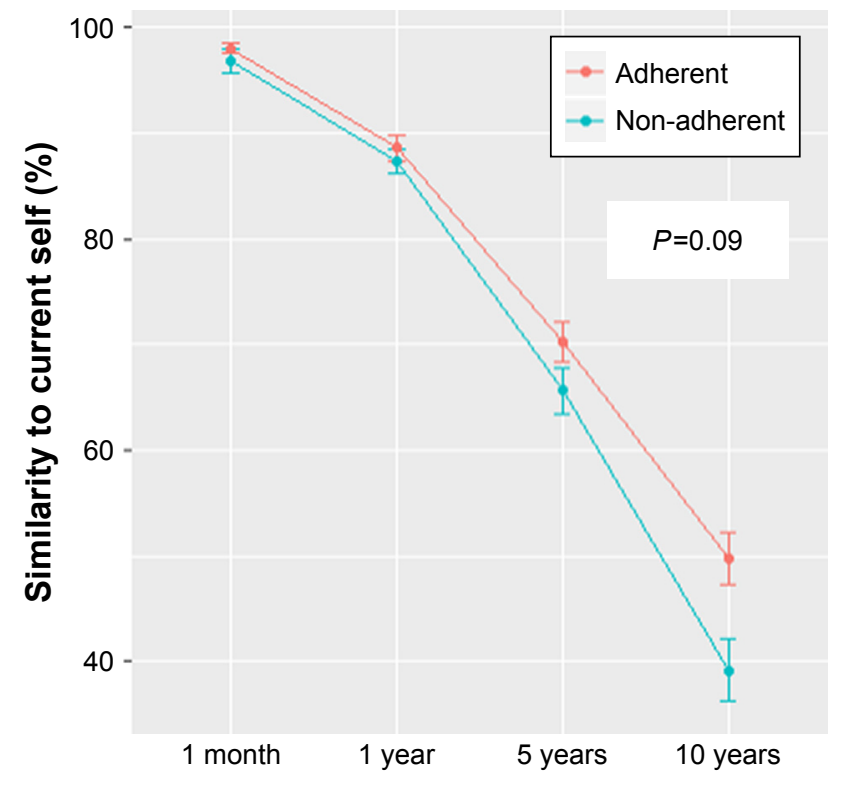

Figure I Evolution of the degree of similarity over time in adherent and nonadherent patients.

Notes: Physical similarity to current self: patients were asked how they thought that they would resemble their current physical aspect in I month, I year, 5 years and 10 years from now and to indicate the $\%$ of similarity. Mean \pm SEM is indicated. Repeated-measures ANOVA were used to perform the comparison of data observed in the adherent and non-adherent patients.

Abbreviation: SEM, standard error of the mean.

$P=0.055)$. When impatience was excluded from the multivariate analysis, two factors were found to be associated with adherence: long temporal horizon (OR, 1.20; 95\% CI, 1.08-1.34; $P<0.001)$ and depression (OR, 0.37; 95\% CI, 0.14-0.96; $P=0.041)$. Figure 2 shows ROC curves for these three models, yielding AUC values of 0.81 (95\% CI,

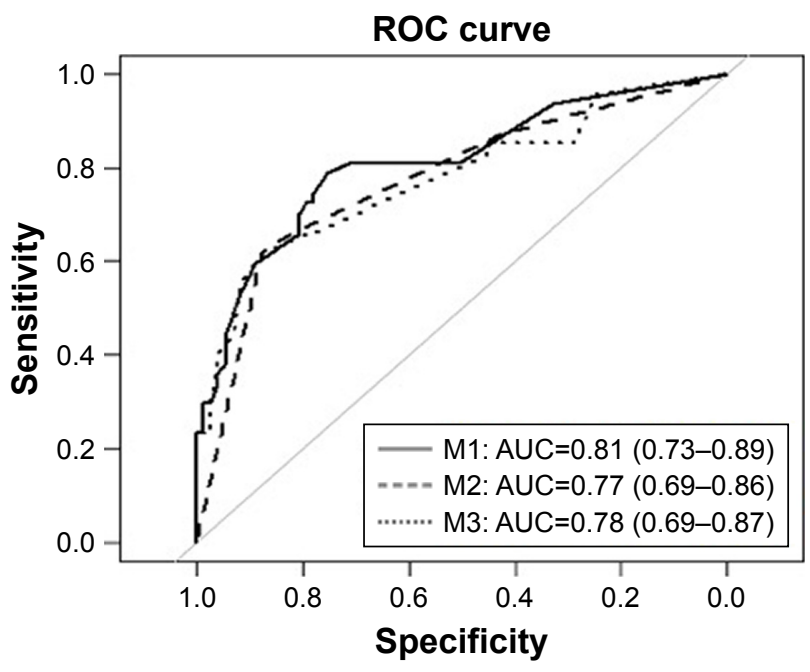

Figure 2 Multivariate analysis of adherence: ROC curves.

Notes: MI: Model that analyzed all parameters with $P<0.10$ in univariate analysis, with the exception of $\mathrm{HbAlc}$. M2: Model that additionally excluded temporal horizon from the analysis. M3: Model that additionally excluded impatience from the analysis. Abbreviation: ROC, receiver operating characteristic.
0.73-0.89), 0.77 (95\% CI, 0.69-0.86) and 0.78 (95\% CI, $0.69-0.87)$, respectively.

\section{Determinants of $\mathrm{HbAlc}$}

In univariate analysis (the results of which are given in Table 4), the following characteristics were associated with $\mathrm{HbA} 1 \mathrm{c} \geq 8 \%$ (64 mmol $/ \mathrm{mol})$ : long temporal horizon (OR, $0.85 ; 0.79-0.92 ; P<0.001)$, non-adherence to medication (OR, 45; 5.67-350.4; $P<0.001)$, impatience in monetary choice (OR, 4.89; 1.7-14.06; $P=0.003$ ) and age $\geq 60$ years old (OR, 0.28; 0.09-0.82; $P=0.021)$. In multivariate analysis, two determinants were associated with $\mathrm{HbA1c} \geq 8 \%$ (64 mmol/mol): non-adherence to medication (OR, 25.05; CI, 3.03-206.75; $P=0.003$ ) and long temporal horizon [OR, $0.90 ; \mathrm{CI}, 0.84-0.98 ; P=0.011$, AUC of the ROC curve $=0.89$ (CI 0.82-0.97)].

\section{Determinants of temporal horizon}

In univariate analysis (Table 5), long temporal horizon as determined by the event method was associated with long temporal horizon as determined by the story method (RR, 1.22; 95\% CI, 1.17-1.27; $P<0.001$ ), non-adherence to medication (RR, $0.31 ; 95 \% \mathrm{CI}, 0.23-0.43 ; P<0.001$ ), a high HbA1c level (RR, 0.30; 95\% CI 0.20-0.46; $P<0.001$ ), impatience (RR, 0.31; 95\% CI, 0.23-0.43; $P<0.001$ ), existence of grandchildren (RR, 2.09; 95\% CI 1.47-2.97; $P<0.001$ ), high score for depression (RR, 0.39; 95\% CI $0.27-0.57 ; P<0.001)$, sadness $(0.49 ; 0.33-0.73 ; P<0.001)$, pessimism $(0.47 ; 0.31-0.70 ; P<0.001)$, social deprivation (RR, 0.47; 95\% CI 0.33-0.67; $P<0.001$ ), older age (RR, $1.92 ; 1.35-2.74 ; P<0.001)$ and high degree of physical similarity at 1 year $(1.02 ; 1.00-1.03 ; P=0.048), 5$ years (1.01; $1.00-1.02 ; P=0.004)$ and 10 years $(R R, 1.01 ; 95 \%$ CI, $1.00-1.02 ; P=0.001)$. In the multivariate analysis, three variables were associated with long temporal horizon: nonadherence to medication (RR, 0.49; 95\% CI, 0.35-0.70; $P<0.001$ ), impatience (RR, 0.051; 95\% CI 0.36-0.72; $P<0.001)$ and existence of grandchildren (RR, 1.61; 95\% CI 1.20-2.17; $P=0.002$ ).

\section{Determinants of impatience}

Similarly, in univariate analysis (Table 6), impatience was to be found associated with long temporal horizon (event method) $(P<0.001)$, non-adherence to medication $(P<0.001)$, high HbA1c level $(P=0.024)$, high score for depression $(P<0.001)$, sadness $(P<0.001)$, pessimism $(P=0.018)$, social deprivation $(P<0.001)$, high physical 
Table 4 Univariate analysis of $\mathrm{HbAlc}$

\begin{tabular}{|c|c|c|c|}
\hline Characteristics & Category & OR $(95 \% \mathrm{CI})$ & $P$-value \\
\hline Age (years) & $\geq 60$ & $0.28(0.09-0.82)$ & 0.021 \\
\hline Adherence (Girerd questionnaire) & Non-adherent & $45(5.67-350.4)$ & $<0.001$ \\
\hline Temporal horizon (events methods) & & $0.85(0.79-0.92)$ & $<0.001$ \\
\hline Answer in the monetary choice & Impatient & $4.89(1.7-14.06)$ & 0.003 \\
\hline Gender & Female & $0.93(0.35-2.48)$ & 0.88 \\
\hline Activity & Stable & $2.65(0.57-12.3)$ & 0.21 \\
\hline Marital status & Couple & $1.85(0.69-5.00)$ & 0.22 \\
\hline Children & Yes & $1.2(0.24-6.06)$ & 0.82 \\
\hline Grandchildren & Yes & $0.47(0.17-1.29)$ & 0.14 \\
\hline BMI & $>24$ & $1.76(0.60-5.18)$ & 0.31 \\
\hline \multirow[t]{3}{*}{ Smoking status } & Quit & 1.00 & \\
\hline & Never & $1.09(0.35-3.39)$ & 0.89 \\
\hline & Active & I.67 (0.42-6.54) & 0.46 \\
\hline Diabetes duration (years) & & $0.99(0.93-1.04)$ & 0.60 \\
\hline Retinopathy & Yes & $\mathrm{I} .68(0.6 \mathrm{I}-4.62)$ & 0.31 \\
\hline Neuropathy & Yes & $0.94(0.35-2.54)$ & 0.91 \\
\hline Stent & Yes & $0.79(0.2-3.08)$ & 0.73 \\
\hline Treatment & Basal insulin & $0.84(0.31-2.25)$ & 0.72 \\
\hline Similarity at I year & & $0.96(0.91-1.02)$ & 0.15 \\
\hline At 5 years & & $0.98(0.96-1.01)$ & 0.21 \\
\hline At 10 years & & $0.99(0.97-1.01)$ & 0.28 \\
\hline Social deprivation (EPICES questionnaire) & Score $>30$ & $2.04(0.72-5.79)$ & 0.18 \\
\hline Depression (Beck Depression Inventory) & Score $>4$ & $2.36(0.73-7.63)$ & 0.15 \\
\hline Sad (Beck Depression Inventory) & Yes & $1.36(0.45-4.09)$ & 0.59 \\
\hline Pessimistic (Beck Depression Inventory) & Yes & $\mathrm{I} .66(0.5 \mathrm{I}-5.4 \mathrm{I})$ & 0.40 \\
\hline
\end{tabular}

Note: Bold figures represent statistically significant.

Abbreviation: BMI, body mass index.

Table 5 Univariate analysis of temporal horizon (events method)

\begin{tabular}{|c|c|c|c|}
\hline Characteristics & Category & OR $(95 \% \mathrm{CI})$ & $P$-value \\
\hline Age (years) & $\geq 60$ & $1.92(1.35-2.74)$ & $<0.001$ \\
\hline Grandchildren & Yes & $2.09(1.47-2.97)$ & $<0.001$ \\
\hline $\mathrm{HbAlc}$ & $\geq 8 \%(64 \mathrm{mmol} / \mathrm{mol})$ & $0.30(0.20-0.46)$ & $<0.001$ \\
\hline Adherence (Girerd questionnaire) & Non-adherent & $0.31(0.23-0.43)$ & $<0.001$ \\
\hline Temporal horizon (stories method) & & $1.22(1.17-1.27)$ & $<0.001$ \\
\hline Similarity at I year & & $1.02(1.00-1.03)$ & 0.048 \\
\hline At 5 years & & $1.01(1.00-1.02)$ & 0.004 \\
\hline At 10 years & & $1.01(1.00-1.02)$ & 0.001 \\
\hline Social deprivation (EPICES questionnaire) & Yes & $0.47(0.33-0.67)$ & $<0.001$ \\
\hline Monetary choice & Impatient & $0.31(0.23-0.43)$ & $<0.001$ \\
\hline Depression (Beck Depression Inventory) & Yes & $0.39(0.27-0.57)$ & $<0.00$ I \\
\hline Sadness & Yes & $0.49(0.33-0.73)$ & $<0.001$ \\
\hline Pessimistic & Yes & $0.47(0.31-0.70)$ & $<0.001$ \\
\hline Marital status & Couple & $1.35(0.92-1.98)$ & 0.13 \\
\hline Children & Yes & $1.34(0.70-2.58)$ & 0.37 \\
\hline BMI & $>24$ & $1.03(0.67-1.6 I)$ & 0.88 \\
\hline \multirow[t]{3}{*}{ Smoking status } & Quit & 1 & \\
\hline & Never & $0.73(0.47-1.13)$ & 0.15 \\
\hline & Active & $0.7(0.43-1.14)$ & 0.15 \\
\hline Diabetes duration (years) & & $1.02(1.00-1.04)$ & 0.056 \\
\hline Retinopathy & Yes & $1.16(0.8-1.67)$ & 0.44 \\
\hline Neuropathy & Yes & $1.65(1.15-2.38)$ & 0.007 \\
\hline Stent & Yes & $\mathrm{I} .43(0.85-2.4 \mathrm{I})$ & 0.18 \\
\hline Treatment & Basal insulin & $1.16(0.8-1.67)$ & 0.43 \\
\hline
\end{tabular}

Note: Bold figures represent statistically significant.

Abbreviation: BMI, body mass index. 
Table 6 Univariate analysis of impatience

\begin{tabular}{|c|c|c|c|}
\hline Characteristics & Category & OR (95\% Cl) & $P$-value \\
\hline Age (years) & $\geq 60$ & $0.62(0.36-1.05)$ & 0.07 \\
\hline Gender & Female & $2.15(1.23-3.75)$ & 0.007 \\
\hline Grandchildren & Yes & $0.89(0.53-|.5|)$ & 0.68 \\
\hline $\mathrm{HbAlc}$ & $\geq 8 \%(64 \mathrm{mmol} / \mathrm{L})$ & $1.23(1.03-1.47)$ & 0.024 \\
\hline Adherence (Girerd questionnaire) & Non-adherent & $2.17(1.59-2.96)$ & $<0.001$ \\
\hline Temporal horizon (event method) & & $0.82(0.74-0.90)$ & $<0.001$ \\
\hline Similarity at I year & & $0.98(0.95-1.01)$ & 0.28 \\
\hline At 5 years & & $0.97(0.94-0.99)$ & 0.006 \\
\hline At 10 years & & $0.97(0.96-0.99)$ & $<0.001$ \\
\hline Social deprivation (EPICES questionnaire) & Yes & II.49 (4.3I-30.65) & $<0.001$ \\
\hline Depression (Beck Depression Inventory) & Yes & $6.01(2.27-15.87)$ & $<0.001$ \\
\hline Sadness & Yes & $8.1(2.63-24.88)$ & $<0.001$ \\
\hline Pessimistic & Yes & $3.08(1.21-7.84)$ & 0.018 \\
\hline Marital status & Couple & $0.27(0.11-0.67)$ & 0.004 \\
\hline Children & Yes & $0.71(0.27-1.90)$ & 0.50 \\
\hline $\mathrm{BMI}$ & $>24$ & $0.66(0.25-1.73)$ & 0.40 \\
\hline \multirow[t]{3}{*}{ Smoking status } & Quit & I & \\
\hline & Never & $1.65(0.66-4.13)$ & 0.29 \\
\hline & Active & $0.73(0.28-1.93)$ & 0.53 \\
\hline Diabetes duration (years) & & $0.96(0.92-1.00)$ & 0.066 \\
\hline Retinopathy & Yes & $0.74(0.35-1.56)$ & 0.43 \\
\hline Neuropathy & Yes & $0.74(0.35-1.57)$ & 0.43 \\
\hline Stent & Yes & $1.32(0.43-4.08)$ & 0.63 \\
\hline Treatment & Basal insulin & $0.98(0.46-2.06)$ & 0.95 \\
\hline
\end{tabular}

Note: Bold figures represent statistically significant. Abbreviation: BMI, body mass index.

similarity at $5(P=0.006)$ and 10 years $(P<0.001)$ and gender, with women giving the impatient answer more often in the fictive monetary scenario $(\mathrm{OR}=2.15 ; 95 \% \mathrm{CI}, 1.23-3.75$; $P=0.007)$. In multivariate analysis, four variables were associated with impatience: social deprivation (OR, 12.92; 95\% CI 3.61-46.29; $P<0.001)$, non-adherence to medication (OR=2.17; 95\% CI, 1.41-3.34; $P<0.001$ ), female gender (OR, 6.78; 95\% CI 1.97-23.29; $P=0.002$ ) and long temporal horizon (event method) which was negatively associated with impatience (RR, 0.86; 95\% CI 0.73-1.00; $P=0.05$ ).

\section{MCA}

MCA was used to detect and systematically explore, without an a priori hypothesis, the relationships among the different variables identified as relevant in the previous analysis. Three typologies were identified (Figure 3 and Table 7). The first group of patients $(n=26)$ were characterized by adherence, $\mathrm{HbA} 1 \mathrm{c}<8 \%$ ( $64 \mathrm{mmol} / \mathrm{mol})$, older age, existence of grandchildren, long-duration diabetes, temporal horizon $>5$ years and patience in the monetary choice. These patients were not socially deprived, depressed, sad or pessimistic, according to their responses to Beck's questionnaire. They had quit smoking.
There were two typologies of non-adherent patients. The first group $(n=59)$ were, like the group of adherent patients, not socially deprived, not depressed, sad or pessimistic; however, they were younger, had shorter diabetes duration and had no grandchildren. They had an intermediate temporal horizon ( $2-5$ years); their $\mathrm{HbAl} \mathrm{c}$ was $\geq 8 \%(64 \mathrm{mmol} / \mathrm{mol})$; these patients either never smoked or were active smokers. The second group of non-adherent patients $(n=35)$ exhibited the shortest temporal horizon ( $\leq 1$ year), impatience and low physical similarity at 10 years. They were socially deprived, depressed and gave sad and pessimistic answers in the Beck's questionnaire.

\section{Discussion Main conclusion}

This study was performed in hospitalized people with diabetes. Only one-third of the participants were adherent to medication. This rate of adherence was half of that reported in another study, also using the Girerd questionnaire, which was performed with the ENTRED cohort $(n=3,767)$, representative of French residents with type 2 diabetes, having a mean $\mathrm{HbA} 1 \mathrm{c}$ level of $7.0 \%$ ( $56 \mathrm{mmol} / \mathrm{mol})$. In this population, $88 \%$ of the patients gave fewer than three positive answers to the 


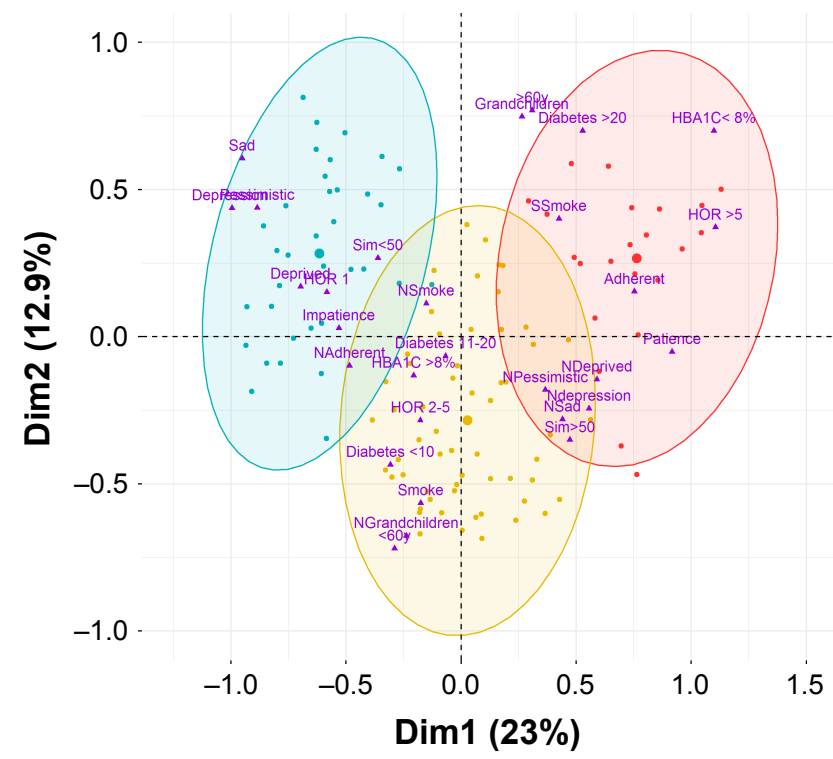

Groups

$\square$ Adherent $\square$ Non-adherent (1) $\square$ Non-adherent (2)

Figure 3 Multiplecorrespondence analysis.

Notes: $\operatorname{Sim}<50$ : I0-year similarity $\leq 50 \%$. HOR I: temporal horizon $\leq$ I year. NAdherent: non-adherent. NSmoke: never smoked. Diabetes II-20: diabetes duration I I-20 years. Hor 2-5: temporal horizon 2-5 years. Diabetes $<10$ : diabetes duration $\leq 10$ years. Smoke: still smoking. NGrandchildren: no grandchildren. $<60 y$ : age $<60$ years old. Sim $>50$ : 10 -year similarity $>50 \%$. Ndepression: no depression. NSad: no sad answer in the Beck questionnaire. Npessimistic: no pessimistic answer in the Beck questionnaire. NDeprived: not socially deprived. SSmoke: quit smoking. HOR $>5$ : temporal horizon $>5$ years. Diabetes $>20$ : diabetes duration $>20$ years. $>60 y$ : age $\geq 60$ years old. Each small dot represents a patient. Large dots represent the centers of typologies.

Girerd questionnaire. ${ }^{19}$ The lower rate of adherence (39.2\%) we report here is consistent with poorer metabolic control in these patients (mean $\mathrm{HbA} 1 \mathrm{c} 9.8 \%$ ), as adherence and $\mathrm{HbA} 1 \mathrm{c}$ were demonstrated to be associated in the ENTRED study, ${ }^{19}$ and it is also consistent with the known association between non-adherence and hospitalization. ${ }^{2}$
We observed, uniquely, an association between adherence to medication and patients' time projection. This was shown for two constructs describing time projection, patience and temporal horizon, which were the only two factors remaining to be associated with adherence to medication in multivariate analysis. This study also provided evidence of a link of adherence to medication and ability to imagine oneself physically in the future, to social deprivation and to depression.

\section{Confirmation of known data and the novelty of this study}

The association between impatience in monetary choice and adherence to medication is not new. We had demonstrated this link earlier in a cohort of 90 people with type 2 diabetes, ${ }^{15}$ and this finding was later confirmed in a multicentric study. ${ }^{20}$ These two studies also showed an association between impatience in monetary choice and poor metabolic control, as evaluated by $\mathrm{HbA} 1 \mathrm{c}$ level, and the data presented in this report confirm this association. An association between impatience in monetary choice and medication adherence has also been demonstrated in asthma. ${ }^{21}$

By contrast, the link between temporal horizon and adherence to medication and HbAlc is novel because this construct has only been tested previously in the context of smoking. ${ }^{13}$ The two constructs, patience/impatience and temporal horizon, may represent two aspects of time projection, namely, short- and long-term projection, respectively. The concept of expected physical similarity to current self, the third aspect of time projection, was investigated by Frederick, ${ }^{16}$ who found that decreases in this value over time were sharper in younger people, especially in teenagers. However, Frederick observed no association between estimations of the degree of connection of now-me and future-me to the

Table 7 The three typologies of patients revealed by the multiple correspondence analysis

\begin{tabular}{|c|c|c|}
\hline Adherent $(n=26)$ & Non-adherent (I) $(n=59)$ & Non-adherent (2) $(n=35)$ \\
\hline Age $\geq 60$ years old & Age $<60$ years old & \\
\hline $\begin{array}{l}\text { Diabetes duration } \\
>20 \text { years }\end{array}$ & $\begin{array}{l}\text { Diabetes duration } \\
\text { I } \mid-20 \text { years }\end{array}$ & \\
\hline Temporal horizon $>5$ years & Temporal horizon $2-5$ years & Temporal horizon $\leq \mathrm{I}$ year \\
\hline Similarity $>50 \%$ in 10 years & & Similarity in 10 years $\leq 50 \%$ \\
\hline Patient & & Impatient \\
\hline Grandchildren & No grandchildren & \\
\hline $\mathrm{HbAlc}<8 \%(64 \mathrm{mmol} / \mathrm{mol})$ & $\mathrm{HbAlc} \geq 8 \%(64 \mathrm{mmol} / \mathrm{mol})$ & \\
\hline Not socially deprived & & Socially deprived \\
\hline Not depressed & & Depressed \\
\hline Not sad & & Sad \\
\hline Not pessimistic & & Pessimistic \\
\hline Quit smoking & Never smoked or still smoke & \\
\hline
\end{tabular}


discount rate for the future in an intertemporal choice experiment. ${ }^{16}$ Therefore, the link between the degree of similarity over time at 10 years and adherence, shown in the MCA undertaken in this study, is also novel. This link makes sense because adherence to long-term therapies may presuppose being able to imagine the future-me that I want to protect. ${ }^{22}$

Interestingly, the link between adherence and depression, present in the univariate analysis, was not confirmed in the multivariate analysis. However, when temporal horizon and impatience were excluded from multivariate analysis, depression was found to be an independent determinant of non-adherence. This is consistent with the link found between depression and perturbations in time projection. ${ }^{23}$ Similarly, although social deprivation was shown to be associated with non-adherence to medication in univariate analysis, it was not present for any of the three models of multivariate analysis. Altogether, these data suggest that the effects of depression ${ }^{24}$ and social deprivation ${ }^{10}$ on patient adherence to long-term medication therapy is largely mediated by disturbance in time projection, which is consistent with deprivation being an independent factor associated with impatience, observed herein.

We observed in multivariate analysis that women gave an impatient answer more frequently than men in the monetary scenario $(P=0.002)$. In literature, conflicting results have been found for the relationship between gender and time discounting: ${ }^{25}$ during their reproductive period, women seem to exhibit patient behavior, but only in the follicular phase. ${ }^{26}$ Thus, this finding may not be relevant for the women involved in this study, who tended to be older.

MCA provided further demonstration of the importance of time projection in orienting patients towards adherent or non-adherent behavior, as shown by the difference between the group of adherent patients and the first group of nonadherent patients, who were not experiencing social deprivation or depression. The main differences between these two groups of patients were the length of temporal horizon and existence of grandchildren, and the age and diabetes duration, which were lesser in non-adherent patients. One is tempted to speculate that the non-adherent patients in this group might become adherent later. They differed from a second group of non-adherent patients, who were characterized by the shortest temporal horizon of all, low expected physical similarity at 10 years and the presence of social deprivation, depression, sadness and pessimism. This cluster may indicate a more severe form of disruption in time projection (Table 7).

We must stress again that this study was performed in hospitalized patients who, therefore, were implicitly selected for a low rate of adherence and poor metabolic control. This had the advantage of ensuring the subjects were a more homogeneous group, making it possible to find unique links between time projection and patient adherence. However, different results may be observed in other settings. Thus, we recently published a study ${ }^{27}$ performed on type 2 diabetes patients, who participated in a health survey panel on a regular basis and had, in general, well-controlled diabetes (mean HbA1c 7.15\% [55 mmol/mol], median=6.65\%) and low rates of non-adherence. In this setting, we observed, in an MCA, that adherent but socially deprived patients had little projection in the distant future (event method), suggesting that there is an effect of social deprivation on the personal temporal horizon, which would be consistent with the data we have reported herein. We also found that patience in monetary choice was associated with adherence, which is also consistent with the data presented here. However, in this study, non-adherent patients who, in general, were socially deprived, projected themselves well in the future, using the event method. To explain this unexpected observation, we speculated that there was effect of denial, which would be consistent with the fact that the story method, which evaluates the temporal horizon of someone else, did not show this effect.

In summary, although it has had initial negative reports, ${ }^{28}$ we found that impatience in monetary choice is related to adherence to medication in diabetes ${ }^{15,20,27}$ and asthma, ${ }^{21}$ as well as to obesity, ${ }^{29}$ being overweight ${ }^{30,31}$ and to various addictions. ${ }^{32}$ Short temporal horizon is linked to smoking habits, ${ }^{13}$ which are then linked to adherence. ${ }^{33}$ Finally, in another study performed in obese people with type 2 diabetes, we observed that self-declaration of prioritization of the future was linked to adherence to medication in an MCA. ${ }^{34}$ Taken together, this accumulation of evidence renders plausible the concept that disruption in time projection is a factor in the determination of patient non-adherence to long-term therapies and can lead to the most severe forms of chronic diseases.

\section{Limitations}

This study was monocentric and cross-sectional, relying, as do many studies in this area, on self-report data without direct assessment. Furthermore, we excluded a priori those patients who were unable to read or understand the questionnaire. Additionally, explanations given to participants who had difficulty in understanding some questions, to avoid missing data, may have influenced the responses. The order of the questions may also have influenced the answers. However, 
the data presented herein should nevertheless be robust enough to stimulate confirmatory studies.

\section{Disruption in time projection: significance of the concept Disruption in time projection as a player in both intentional and unintentional non- adherence}

Adherence to long-term therapy has often been explained using socio-cognitive models, such as the Health Belief Model, ${ }^{35}$ the Theory of Planned Behavior, ${ }^{36}$ the Social Learning Theory, ${ }^{37}$ and the Necessity-Concerns Framework. ${ }^{38}$ Alongside these models, where non-adherence is largely "intentional", it has also been suggested that some forms of non-adherence may be "unintentional": 39 in the first case, patients, after weighing pros and cons, make a rational choice not to adhere while, for its part, unintentional non-adherence does not depend on the choice of the patient but on factors such as poor understanding of the prescription, difficulty of access to the prescribed medication, intervention of the patient's habits, lack of memory, defense mechanisms or simply irrationality. ${ }^{12}$ In general, these unintentional aspects of non-adherence are not explored in cognitive questionnaires, such as the Beliefs about Medicine Questionnaire $^{40}$ or the Adherence Barriers Questionnaire. ${ }^{41}$

We propose that disruption in time projection, as described in this paper, plays a role in both intentional and unintentional non-adherence. Some people with disruption in time projection may prefer, either as a personal choice or under the pressure of external elements, such as social deprivation, to prioritize immediate rewards, ie, making a choice not to adhere. Others may not be conscious of the disruption in time projection they experience, which could, thus, be a novel source of cognitive bias ${ }^{42,43}$ and, therefore, play a role in unintentional non-adherence. Incidentally, this dual effect on non-adherence represents a new argument for revisiting the distinction between intentional and unintentional non-adherence. ${ }^{44}$

\section{Disruption in time projection as a loss of a protective mechanism: evolutionary insight into adherence}

Time-projection ability may develop early in some children, as shown by Mischel's marshmallow test experiment, in which the ability to delay gratification at the age of 4 was shown to be linked to future positive outcomes, such as physical and psychological health, social competence and academic success. ${ }^{45}$ The ability to delay gratification may have a neuronal basis, ie, the progressive development of the prefrontal cortex, the seat of the executive functions, which marks the transition from the adolescent to the adult brain, ${ }^{46}$ or it may even have a genetic basis. ${ }^{47,48}$ Evolutionarily, the development of foresight could represent a culmination of the hominization of Homo sapiens sapiens, who is endowed with reflexivity. ${ }^{49}$ We suggest that this time-projection ability, which was a protective mechanism in pre-historical times, is now an element in being a "healthy adherer", and it explains the lower mortality rates in people adherent to a placebo. ${ }^{50}$ In this general conceptual framework, disruption in time projection, whether innate or acquired, could result in a loss of this protective mechanism, leading to non-adherence to long-term therapies in chronic diseases.

\section{Conclusion}

\section{Implications for medical practice}

The link found between disruption in time projection and nonadherence to long-term medication therapies shown in this study may have important practical implications for teaching and practice of medicine. First, it may be important to present to "impatient patients" short-term rewards for adherence instead of the avoidance of long-term complications of their diseases. Next, giving full significance to the term chronic disease, this construct completes the bio-psychosocial model of medicine, ${ }^{51}$ showing the importance of accounting specifically for various aspects of time projection, in addition to the potential deleterious effect of depression and social deprivation.

The general concept of person-centred medicine ${ }^{52}$ encompasses temporality. Indeed, the philosopher Derek Parfit proposed that psychological continuity over time is what defines a person. ${ }^{22}$ Thus, future doctors should be taught to ask patients not only about their history but also how they consider their future to enable diagnosis of the condition we termed here "disruption in time projection", with its three components: patience, temporal horizon and expected degree of physical similarity to one's self in the future.

\section{Author contributions}

GR designed the study and its analysis and wrote the paper. $\mathrm{YB}$ administered the questionnaire to patients and $\mathrm{MB}$ performed the statistical analysis. GR, YB, MB and VL contributed to data analysis, drafting and revising the article, gave final approval of the version to be published, and agree to be accountable for all aspects of the work. No specific funding was provided for this study.

\section{Disclosure}

The authors report no conflicts of interest in this work. 


\section{References}

1. Farmer AJ, Rodgers LR, Lonergan M, et al. Adherence to oral glucoselowering therapies and associations with 1-Year $\mathrm{HbA1c}$ : A retrospective cohort analysis in a large primary care database. Diabetes Care. 2016; 39(2):258-263.

2. Curtis SE, Boye KS, Lage MJ, Garcia-Perez LE. Medication adherence and improved outcomes among patients with type 2 diabetes. Am J Manag Care. 2017;23(7):e208-e214.

3. Khunti K, Seidu S, Kunutsor S, Davies M. Association between adherence to pharmacotherapy and outcomes in type 2 diabetes: a metaanalysis. Diabetes Care. 2017;40(11):1588-1596.

4. Sabaté E. Adherence to Long Term Therapies, Evidence for Action. Geneva: WHO Library Cataloguing-in-Publication Data; 2003:211.

5. Safran DG, Taira DA, Rogers WH, et al. Linking primary care performance to outcomes of care. J Fam Pract. 1998;47(3):213-220.

6. Bonds DE, Camacho F, Bell RA, Duren-Winfield VT, Anderson RT, Goff DC. The association of patient trust and self-care among patients with diabetes mellitus. BMC Fam Pract. 2004;5:26.

7. Nguyen GC, Laveist TA, Harris ML, et al. Patient trust-in-physician and race are predictors of adherence to medical management in inflammatory bowel disease. Inflamm Bowel Dis. 2009;15(8):1233-1239.

8. Reach G. Obstacles to patient education in chronic diseases: a transtheoretical analysis. Patient Educ Couns. 2009;77(2):192-196.

9. Briesacher BA, Andrade SE, Fouayzi H, Chan KA. Comparison of drug adherence rates among patients with seven different medical conditions. Pharmacotherapy. 2008;28(4):437-443.

10. Wamala S, Merlo J, Bostrom G, Hogstedt C, Agren G. Socioeconomic disadvantage and primary non-adherence with medication in Sweden. Int J Qual Health Care. 2007;19(3):134-140.

11. Reach G. A novel conceptual framework for understanding the mechanism of adherence to long term therapies. Patient Prefer Adherence. 2008;2:7-20.

12. Reach G. The Mental Mechanisms of Patient Adherence to Long-Term Therapies, Mind and Care, Foreword by Pascal Engel, Philosophy and Medicine. Heidelberg: Springer; 2015:207.

13. Jones BA, Landes RD, Yi R, Bickel WK. Temporal horizon: modulation by smoking status and gender. Drug Alcohol Depend. 2009; 104 Suppl 1:S87-S93.

14. Girerd X, Hanon O, Anagnostopoulos K, Ciupek C, Mourad JJ, Consoli S. Assessment of antihypertensive compliance using a selfadministered questionnaire: development and use in a hypertension clinic. Presse Med. 2001;30(21):1044-1048. French.

15. Reach G, Michault A, Bihan H, Paulino C, Cohen R, Le Clésiau H. Patients' impatience is an independent determinant of poor diabetes control. Diabetes Metab. 2011;37(6):497-504.

16. Frederick S. Time preference and personal identity. In: Loewenstein G, Read D, Baumeister RF, editors. Time and Decision. New York: Russel Sage Foundation; 2003.

17. Sass C, Guéguen R, Moulin JJ, et al. Comparison of the individual deprivation index of the French Health Examination Centres and the administrative definition of deprivation. Sante Publique. 2006;18(4):513-522. French.

18. Beck AT, Beck RW. Screening depressed patients in family practice. A rapid technic. Postgrad Med. 1972;52(6):81-85.

19. Tiv M, Viel JF, Mauny F, et al. Medication adherence in type 2 diabetes: the ENTRED study 2007, a French Population-Based Study. PLoS One. 2012;7(3):e32412.

20. Lebeau G, Consoli SM, Le Bouc R, et al. Delay discounting of gains and losses, glycemic control and therapeutic adherence in type 2 diabetes. Behav Processes. 2016;132:42-48.

21. Brandt S, Dickinson B. Time and risk preferences and the use of asthma controller medication. Pediatrics. 2013;131(4):e1204-e1210.

22. Parfit D. Reasons and Persons. Oxford: Clarendon Press; 1984.

23. Gorwood P. Depressed patients and their notion of time. Medicographia. 2010;32:133-137.
24. Goldstein CM, Gathright EC, Garcia S. Relationship between depression and medication adherence in cardiovascular disease: the perfect challenge for the integrated care team. Patient Prefer Adherence. 2017;11:547-559.

25. Silverman IW. Gender differences in delay gratification: a meta-analysis. Sex Roles. 2003;49(9/10):451-463.

26. Hosseini-Kamkar N, Morton JB, Bruce Morton J. Sex differences in selfregulation: an evolutionary perspective. Front Neurosci. 2014;8:1-8.

27. Reach G, Pellan M, Crine A, Touboul C, Ciocca A, Djoudi Y. Holistic psychosocial determinants of adherence to medication in people with type 2 diabetes. Diabetes Metab. 2018. Epub 2018 Jun 20.

28. Chapman GB, Brewer NT, Coups EJ, Brownlee S, Leventhal H, Leventhal EA. Value for the future and preventive health behavior. J Exp Psychol Appl. 200;7:235-250.

29. Weller RE, Cook EW, Avsar KB, Cox JE. Obese women show greater delay discounting than healthy-weight women. Appetite. 2008; 51(3):563-569.

30. Ikeda S, Kang MI, Ohtake F. Hyperbolic discounting, the sign effect, and the body mass index. J Health Econ. 2010;29(2):268-284.

31. Bénard M, Camilleri G, Etilé F, et al. Association between impulsivity and weight status in a general population. Nutrients. 2017; 9(3):E217.

32. Perry JL, Carroll ME. The role of impulsive behavior in drug abuse. Psychopharmacology. 2008;200(1):1-26.

33. Solberg LI, Desai JR, O’Connor PJ, Bishop DB, Devlin HM. Diabetic patients who smoke: are they different? Ann Fam Med. 2004;2(1):26-32.

34. Reach G. Obedience and motivation as mechanisms for adherence to medication: a study in obese type 2 diabetic patients. Patient Prefer Adherence. 2011;5:523-531.

35. Becker MH, Maiman LA. Sociobehavioral determinants of compliance with health and medical care recommendations. Med Care. 1975;13(1):10-24.

36. Fishbein M, Ajzen I. Belief, Attitude, Intention and Behavior. Don Mills, NY: Addison-Wesley; 1975.

37. Bandura A. Social cognitive theory of moral thought and action. In: Kurtines WM, Gewirtz JL, editors. Handbook of Moral Behavior and Development. Vol. 1. Hillsdale, NJ: Lawrence Erlbaum Associates; 1991: 45-103.

38. Horne R, Chapman SCE, Parham R, Freemantle N, Forbes A, Cooper V. Understanding patients' adherence-related beliefs about medicines prescribed for long-term conditions: A meta-analytic review of the Necessity-Concerns Framework. PLoS One. 2013;8(12):e80633.

39. Lehane E, McCarthy G. Intentional and unintentional medication nonadherence: A comprehensive framework for clinical research and practice? A discussion paper. Int J Nurs Stud. 2007;44(8):1468-1477.

40. Horne R, Weinman J, Hankins M. The beliefs about medicines questionnaire: The development and evaluation of a new method for assessing the cognitive representation of medication. Psychol Health. 1999;14(1):1-24.

41. Müller S, Kohlmann T, Wilke T. Validation of the Adherence Barriers Questionnaire - an instrument for identifying potential risk factors associated with medication-related non-adherence. BMC Health Serv Res. 2015;15(1):153.

42. Tversky A, Kahneman D. Judgment under uncertainty: heuristics and biases. Science. 1974;185(4157):1124-1131.

43. Kahneman D, Tversky A. Prospect theory: an analysis of decision under risk. Econometrica. 1979;47(2):263-291.

44. Gadkari AS, McHorney CA. Unintentional non-adherence to chronic prescription medications: How unintentional is it really? BMC Health Services Research. 2012;12:98-109.

45. Mischel W, Shoda Y, Rodriguez M. Delay of gratification in children. Science. 1989;244(4907):933-938.

46. Frost R, McNaughton N. The neural basis of delay discounting: A review and preliminary model. Neuroscience \& Biobehavioral Reviews. 2017;79:48-65.

47. Reach G. Is there an impatience genotype leading to non-adherence to long-term therapies? Diabetologia. 2010;53(8):1562-1567. 
48. MacKillop J. Integrating behavioral economics and behavioral genetics: delayed reward discounting as an endophenotype for addictive disorders. J Exp Anal Behav. 2013;99(1):14-31. Epub 2012 Dec 5.

49. Frankfurt HG. Freedom of the will and the concept of a person. JPhilos. 1971;68(1):5-20.

50. Simpson SH, Eurich DT, Majumdar SR, et al. A meta-analysis of the association between adherence to drug therapy and mortality. BMJ. 2006;333(7557):15
51. Engel G. The need for a new medical model: a challenge for biomedicine. Science. 1977;196(4286):129-136.

52. Entwistle VA, Watt IS. Treating patients as persons: a capabilities approach to support delivery of person-centered care. Am J Bioeth. 2013; 13(8):29-39. 


\section{Appendix}

\section{Demographic data}

- You are $\quad$ male $\square \quad$ female $\square$

- Your age: ....... years

- Describe your employment situation: currently,

- your employment is stable $\square$ your employment is unstable $\square$

o you have no employment $\square$ you are retired $\square$ you are in search of employment $\square$

- you are a student $\quad$ yes $\square \quad$ no $\square$

- you are disabled $\quad$ yes $\square \quad$ no $\square$

- You are single $\square$ married $\square$ living as a couple $\square$ divorced $\square$ widow $\square$

- You have children $\quad$ yes $\square \quad$ no $\square$

- You have grandchildren $\quad$ yes $\square \quad$ no $\square$

- Your height: ....... cm Your weight: ....... kg

- $\quad$ Smoking habits: you never smoked $\square$ quit smoking $\square$ smoke $\square$

- You have had diabetes since ....... years (for instance 5 years)

- Last HbA1c level in patient record (completed by the resident after the interview) ....... \%

- $\quad$ Diabetes complications (completed by the resident): retinopathy yes $\square$ no $\square$
- painful neuropathy
yes $\square \quad$ no $\square$
- stent
yes $\square \quad$ no $\square$

\section{Time projection}

Patience/impatience

- If we offered to give you $\in 500$ today or $\in 1,500$ in a year from now, what would you choose? $\in 500$ today $\square \in 1,500$ in a year $\square$

Temporal horizon

- Give a list of at least five events that could happen in your life (example: I will get married) with the age you think you will be when they happen:
- Age:
- Age:
- Age:
- Age:
- Age:

- Here is the beginning of a story: Joe, drinking his coffee, starts to think of the future. He thinks that ...... Complete this story in three to four lines.

What is the duration of what you have imagined?

....... minutes ...... days ....... weeks ....... months ....... years

Similarity to current self

- Do you think that you will physically resemble your current appearance in 1 month, 1 year, 5 years and 10 years?

If your physical appearance completely changes, you would be unable to recognize yourself; this would mean $0 \%$ similarity to your current appearance. If there would be no change at all, this would mean $100 \%$ similarity to your current appearance.

Please rate the percentage of similarity to your current appearance (ranging from $0 \%=$ no similarity at all to $100 \%=$ complete similarity) for each of the following time frames: Degree of similarity (\%)
In 1 month $\%$
In 1 year $\%$
In 5 years
$\%$
In 10 years $\%$

Figure Al Questions asked to the patients to collect their demographic data and to address time projection. Note: Translated from French by the main author.

Patient Preference and Adherence

Dovepress

\section{Publish your work in this journal}

Patient Preference and Adherence is an international, peer-reviewed, open access journal that focuses on the growing importance of patient preference and adherence throughout the therapeutic continuum. Patient satisfaction, acceptability, quality of life, compliance, persistence and their role in developing new therapeutic modalities and compounds to optimize clinical outcomes for existing disease states are major areas of interest for the journal. This journal has been accepted for indexing on PubMed Central. The manuscript management system is completely online and includes a very quick and fair peer-review system, which is all easy to use. Visit http://www. dovepress.com/testimonials.php to read real quotes from published authors.

Submit your manuscript here: http://www.dovepress.com/patient-preference-and-adherence-journal 